\title{
Managing for ocean biodiversity to sustain marine ecosystem services
}

\author{
Stephen R Palumbi ${ }^{*}$, Paul A Sandifer ${ }^{2}$, J David Allan ${ }^{3}$, Michael W Beck ${ }^{4}$, Daphne G Fautin ${ }^{5}$, Michael J Fogarty ${ }^{6}$, \\ Benjamin S Halpern ${ }^{7}$, Lewis S Incze ${ }^{8}$, Jo-Ann Leong ${ }^{9}$, Elliott Norse ${ }^{10}$, John J Stachowicz ${ }^{11}$, and Diana H Wall ${ }^{12}$
}

Managing a complex ecosystem to balance delivery of all of its services is at the heart of ecosystem-based management. But how can this balance be accomplished amidst the conflicting demands of stakeholders, managers, and policy makers? In marine ecosystems, several common ecological mechanisms link biodiversity to ecosystem functioning and to a complex of essential services. As a result, the effects of preserving diversity can be broadly beneficial to a wide spectrum of important ecosystem processes and services, including fisheries, water quality, recreation, and shoreline protection. A management system that conserves diversity will help to accrue more "ecoservice capital" for human use and will maintain a hedge against unanticipated ecosystem changes from natural or anthropogenic causes. Although maintenance of biodiversity cannot be the only goal for ecosystem-based management, it could provide a common currency for evaluating the impacts of different human activities on ecosystem functioning and can act as a critical indicator of ecosystem status.

Front Ecol Environ 2009; 7(4): 204-211, doi:10.1890/070135 (published online 18 Sep 2008)

$\mathrm{C}$ Oompelling evidence is accumulating from terrestrial, freshwater, and marine systems to suggest that sustainable ecosystem services depend upon a diverse biota (Daily et al. 1997; Loreau et al. 2001; Tilman et al. 2001; Wall et al. 2004; MA 2005; Sala and Knowlton 2006; Worm et al. 2006; Butler et al. 2007; Hector and Bagchi 2007). In principle, such knowledge should be useful in guiding a national ocean policy that maintains the ser-

\section{In a nutshell:}

- Natural biodiversity broadly promotes the provision of marine ecosystem functions, including those critical to human survival and well-being

- Conserving natural biodiversity increases the likelihood that marine ecosystems can continue to provide such services and serves as a hedge against environmental change, increasing the chance that ecosystems can adapt and recover following disturbance

- Conserving biodiversity should become a common aim of ecosystem-based management for all agencies involved in regulating the marine environment

- Management for biodiversity may have to rely, in part, on management of surrogates, such as habitat types, population size, and related biodiversity characteristics

${ }^{1}$ Department of Biology, Stanford University, Hopkins Marine Station, Pacific Grove, CA "(spalumbi@stanford.edu); ${ }^{2} \mathrm{NOAA}$ Hollings Marine Laboratory, Charleston, SC; ${ }^{3}$ School of Natural Resources and Environment, University of Michigan, Ann Arbor, MI; ${ }^{4}$ The Nature Conservancy, University of California, Santa Cruz, Santa Cruz, CA; ${ }^{5}$ Division of Biological Sciences, University of Kansas, Laurence, KS; ${ }^{6} \mathrm{NOAA}$ Northeast Fisheries Science Center, Woods Hole, MA; (continued on p211)

Beyond the Frontier: Listen to Stephen Palumbi discussing this research on Frontiers' monthly podcast, at www.frontiersinecology.org. vices provided by oceans into the future. But does knowing the link between diversity and services usefully inform policy? We argue that management to sustain biodiversity could provide a critical foundation for a practical, ecosystem-based management (EBM) approach to the oceans.

Globally, $60 \%$ of ecosystem services are degraded (MA 2005). These ecosystems provide food, shelter, recycling, and other support mechanisms that human communities require, but fundamental services are declining as ecosystems are unraveled by human impacts (Palmer et al. 2004). Marine ecosystems (Figure 1) provide a constellation of services: they produce food, receive and assimilate wastes, protect shorelines from storms, regulate the climate and atmosphere, generate tourism income, and provide recreational opportunities (Covich et al. 2004; MA 2005). The extraordinary diversity of the world's oceans - across the different levels of ecosystems, habitats, species, functional roles, and genetic diversity (Carpenter et al. 2006; Sala and Knowlton 2006) - and the interconnections of marine, coastal, freshwater, and terrestrial ecosystems make managing ocean ecosystems crucial for long-term prosperity. Although degradation of ecosystems might be reversed through appropriate policies (MA 2005), there are substantial information gaps in our understanding of ecosystem processes (Carpenter et al. 2006), which impede practical ideas about implementing policy.

EBM involves incorporating knowledge of ecosystem processes into management, but defining EBM and specifying how it can be implemented has been difficult, particularly for marine ecosystems (Arkema et al. 2006). Grumbine (1994) surveyed 33 definitions of EBM, and Arkema et al. (2006) detailed 17. However, even with this large number of definitions, fewer than $10 \%$ of plans created by resource managers addressed priority EBM cri- 

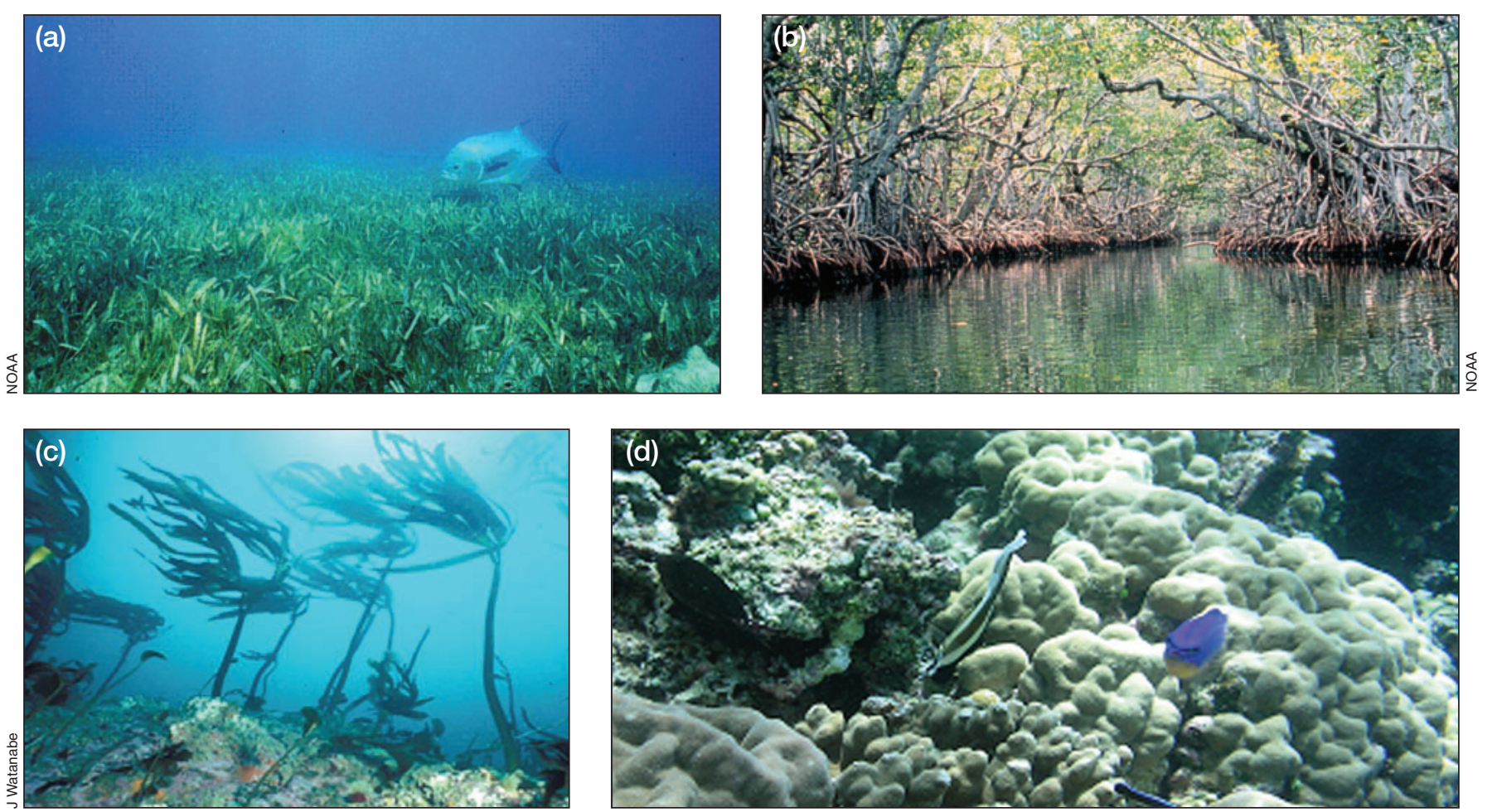

Figure 1. The high diversity of marine habitats provides a wealth of important marine ecosystem services. (a) The species in these grass beds in Florida serve to consolidate sediment, protect shallow shores, and provide nursery and forage grounds for fish. (b) Mangrove forests protect coastlines from wave and tsunami damage, provide wood, shelter juvenile fish, recycle terrestrial runoff, and produce almost as much food per acre as a commercial shrimp farm. These complex services are provided by thousands of plant, animal, and microbial species. (c) Kelp forests and (d) coral reefs are some of the most productive ecosystems on Earth. Recreational, commercial, and subsistence fishing, as well as shore protection and tourism revenue, are derived from these ecosystems.

teria, such as sustainability (Arkema et al. 2006). Despite increasing agreement on the principles and criteria of EBM among academics, managers do not include these in current plans (Arkema et al. 2006). Calls for EBM usually include the need to create a balance between services and to incorporate input from all stakeholders, managers, and policy makers (Arkema et al. 2006). However, this complex balancing act requires a high level of coordination, a great deal of cooperation, and the ability of managers to enforce trade-offs among different services. How can such positive interactions best be achieved? We posit that a common focus on management to conserve natural biodiversity could provide a foundation for such interactions and a practical basis for beginning EBM.

\section{Showing that diversity matters}

Biological diversity includes diversity at genetic, species, and ecosystem levels (Norse and McManus 1980). Sala and Knowlton (2006) succinctly defined marine biodiversity as "the variety of life in the sea, encompassing variation at levels of complexity from within species to across ecosystems". Experiments on, and observations of, species diversity in sessile invertebrates and seaweeds (Stachowicz et al. 2002; Allison 2004), grazing crustaceans (Duffy et al. 2003), and predators (Byrnes et al. 2006), as well as genetic diversity in seagrasses (Hughes and Stachowicz 2004; Reusch et al. 2005), salmon populations (Hilborn et al. 2003), and oceanic cyanobacteria (Coleman et al. 2006), suggest that more diverse assemblages provide either higher productivity, greater resilience, or both. Analyses over larger temporal and spatial scales suggest similar linkages (Sala and Knowlton 2006; Worm et al. 2006). In addition, some of the key elements of ecosystem resilience, such as recovery, resistance, and reversibility, are bolstered by natural levels of biodiversity (Coleman et al. 2006; Palumbi et al. 2008).

These and other studies provide evidence for a generally positive relationship between biodiversity and ecosystem processes and services (Figure 2). A spectrum of mechanisms might generate this positive diversity effect, including complementary resource use, positive interactions among species, and increased likelihood of having key species present when species diversity is high. Ecological research suggests that these mechanisms are commonly in operation in the sea. For example, complementarity, in which species have slightly different roles in their environment, is probably widespread, because of the high frequency of niche partitioning among marine species (Kohn 1959). Facilitation, which occurs when one species improves environmental conditions for others, is well documented in such marine ecosystems as salt marshes, coral reefs, and kelp forests (Knowlton 1999; Bruno et al. 2003). By contrast, in some cases, a single species may play a central (sometimes 


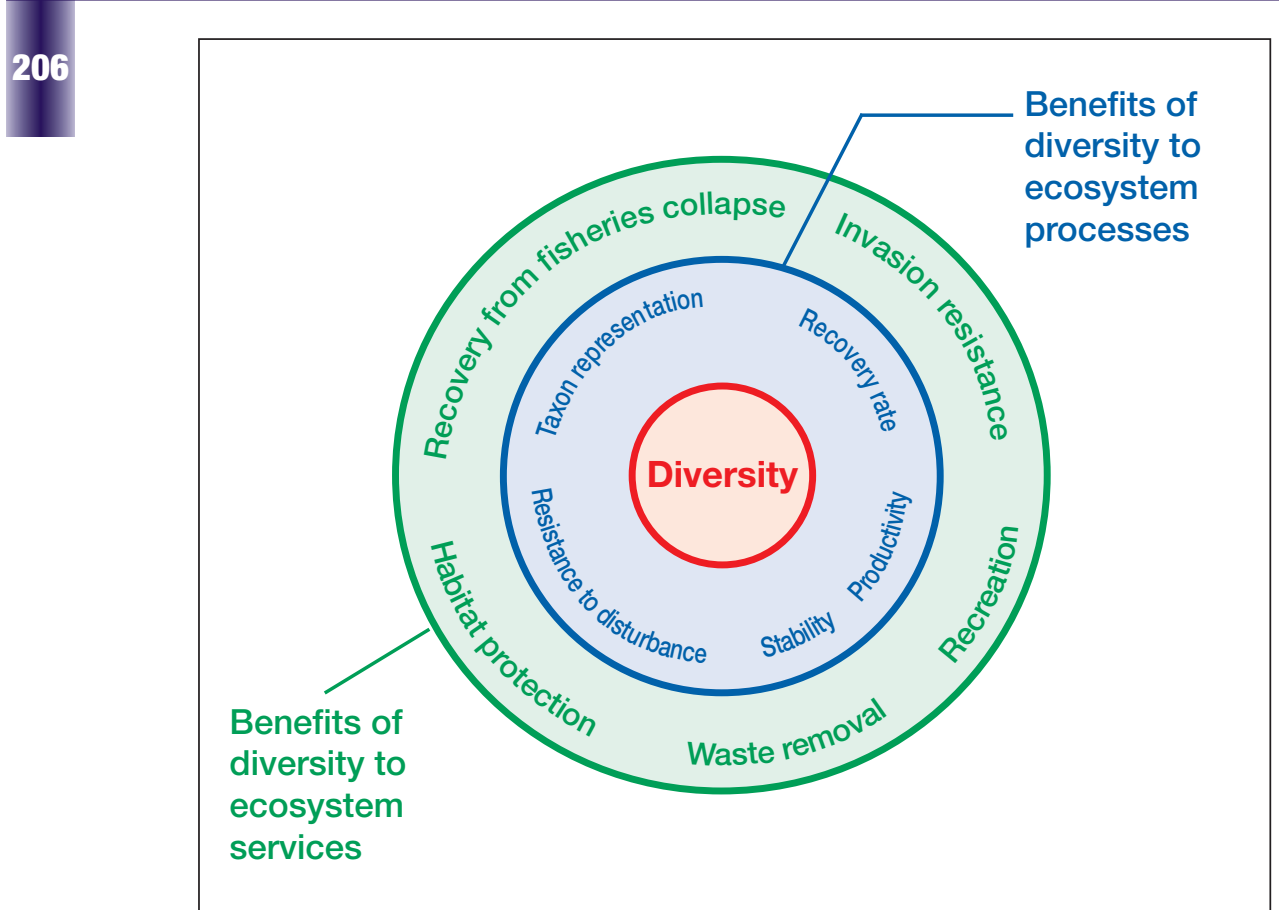

Figure 2. A schematic view of the benefits of biodiversity. Diversity (red ring) enhances a variety of ecological processes (blue ring). These enhanced processes accelerate benefits that ecosystems provide in terms of recovery, resistance, protection, recycling, recreation, etc (green ring). Results are summarized from Loreau et al. (2001); Stachowicz et al. (2002); Duffy et al. (2003); Hilborn et al. (2003); Allison (2004); Hughes and Stachowicz (2004); Wall et al. (2004); Reusch et al. (2005); Byrnes et al. (2006); and Worm et al. (2006) .

through "guilds" or groups of species that perform similar functions within the ecosystem; Naeem and Li 1997). In addition, ecosystem stability may increase with diversity due to a portfolio effect, in which variations are dampened due to statistical averaging (Tilman et al. 2006). We infer that redundancy is common in the sea because many marine species have generalized diets, creating overlapping food web links that may generate a biodiversity insurance effect. Although species cannot be both perfectly complementary and perfectly compensatory, the complex mix of similarities and differences among species often results in a reduction in the fluctuations of ecosystem properties for systems that retain a larger number of slightly different functional elements (Tilman et al. 2006).

Invasive species add complexity to these issues. Although they nominally add to biodiversity by increasing the number of species present, their addition can often have a destabilizing effect on natural community abundance patterns and ecosystem services, especially if they become dominant. In such cases, they are better seen as a disturbance to the community, and we do

called keystone or foundational) role in an ecosystem. For well-known keystone species like sea otters, managing for their abundance is an obvious plan. However, other species play hidden but important roles, with impacts that may vary over time and space. High diversity assemblages have a higher chance of including such species than low diversity assemblages, which also helps to generate a diversity effect (Sala and Knowlton 2006). Structure-forming species, such as corals, oysters, kelps, sea- and marsh grasses, and mangroves, may be especially important, because their physical form provides numerous microhabitats and niches.

Even when high diversity results in species with similar ecological roles, the apparent biological redundancy can provide protection against changes in ecosystem function, because such species are usually not ecologically identical and are not redundant in the typical sense of the word (Levin 1999). Species richness (the number of species) provides a reservoir of biological options that help to ensure that an ecosystem can respond to some level of perturbation without catastrophic failure. This "insurance effect" of species richness is easily observed in ecosystems that are highly disturbed by human intervention (Nystrom and Folke 2001; Tilman et al. 2006), and probably plays a critical role in sustaining functions in these ecosystems. This can occur when similar species respond differently to environmental variation (Yachi and Loreau 1999), or when a substantial reduction in population size of one species is buffered by the presence of backups (eg not include them in our consideration of the role of natural levels of biodiversity in ecosystem function.

\section{Complex services provided by diverse communities}

Even a simple-sounding ecosystem service may depend on complex ecological processes that, in turn, depend on high biological diversity. For example, waste detoxification depends on the breakdown of many pollutants by microbes. The broad range of metabolic processes needed for this action demands a diverse microbial community (Nystrom and Folke 2001).

Most other ecosystem services, including fisheries that target dozens of species simultaneously, also depend on complex ecological linkages. Diversity among and within species can stabilize the delivery of these complex services (Hilborn et al. 2003; Hughes and Stachowicz 2004; Reusch et al. 2005; Palumbi et al. 2008). For example, Worm et al. (2006) showed that marine ecosystems with high diversity had slower fisheries collapse rates and higher rates of fisheries recovery than marine ecosystems with lower diversity.

The link between diversity and services is not limited to the sea. Hector and Bagchi (2007) found that different ecological processes in grassland ecosystems rely on different species. Thus, the list of species considered important to ecosystem function grows with the number of ecosystem functions included in the analysis. Soil biological commu- 
nities also contribute strongly to services such as water quality, food, erosion control, and pollutant degradation (Kibblewhite et al. 2008), suggesting that the link between ecosystem services and biodiversity crosses ecosystem boundaries. Clearly, however, agricultural and aquacultural systems represent situations in which artificial monocultures provide particular services, such as food. Here, the value of one particular service is enhanced at the expense of others. Such trade-offs may be a common feature of detailed management plans in any large ecosystem, but should be considered part of a larger ecological mosaic in which other services are supported by natural biodiversity.

\section{Existing mandates for maintenance of marine biological diversity}

Some authorization to protect marine biodiversity exists for many US federal and state agencies, although the term "biodiversity" may not be specifically mentioned. Relevant US federal laws include the National Environmental Policy Act, Clean Water Act, MagnusonStevens Fishery Conservation and Management Act (MSA), Endangered Species Act (ESA), Marine Mammal Protection Act, and National Marine Sanctuaries Act. However, no single administrative and legislative framework exists for integrated ocean management in the US, despite urgent calls for such a structure (Pew Oceans Commission 2003; USCOP 2004).

Progress toward EBM in fisheries (Pikitch et al. 2004) culminated in the US Administration's commitment to EBM in the US Ocean Action Plan (2004). The central issue is no longer whether to apply an ecosystem approach to management, but rather how to apply it. Current agency efforts are dominated by consideration of harvestable resources, and these are only a fraction of the important ecosystem services at stake. An approach emphasizing the role of biodiversity and multiple services (Figure 2) would be much more comprehensive.

\section{Using diversity to manage multiple, conflicting services}

Here, we propose a fundamental shift in orientation, one that would move us away from management of one service at a time and allow us to focus instead on the conservation of multiple services through protection of natural biodiversity. Biodiversity would become the central element tying management of different sectors together, constraining some sectors for the benefit of others, but ultimately producing a net benefit for all sectors. We argue that consistent management across agencies to sustain natural biodiversity - via conservation of species richness, genetic diversity, species composition, and habitat diversity - will help to maintain ecosystem integrity and stability. Our approach establishes the maintenance of natural biodiversity (sustaining all of an ecosystem's biological parts at functioning levels) as a common core principle, guiding decision mak- ing in agencies at local, state, and federal levels.

The suite of services provided by marine ecosystems can create management conflict and overuse of the environment through cumulative impacts, if different managers are required to optimize for different services. For example, if improving waste management demands changes that decrease fisheries yield, then separate management for these services may generate regulatory conflict and the inability of either management body to reach its goals (Figure 3). Thus, a management focus on one service at a time may compromise the multifunctionality of the ecosystem. So, how can managers balance conflicting needs for a given ecosystem, to produce many complex, linked services?

We suggest an approach based first on the link between diversity and ecosystem function and, second, on experimental studies showing that increased biodiversity can simultaneously increase and stabilize multiple measures of ecosystem functioning (Hooper and Vitousek 1998; Duffy et al. 2003; Worm et al. 2006). In this approach, different agencies, regardless of their primary focus (eg fisheries, water quality, coastal zone management), would also be required to manage for sustained biodiversity, because sustained biodiversity would increase the likelihood that multiple, important ecosystem services would be sustained as well (Figure 3). Such clear mandates will probably need to come in the form of amendments to existing laws or new laws, or could be incorporated into comprehensive ocean area-based management. Although politically difficult, development of such mandates would generate broadly parallel management goals in different agencies, creating much-needed coordination, as agencies would be managing for similar outcomes.

Coupled with a clear specification of other management objectives and establishment of strategies for evaluation of trade-offs and conflicts among different ocean-use sectors, maintenance of biological diversity can serve as a focal point for the specification of management options and constraints on human impacts. Maintenance of biodiversity cannot be the only approach to managing ecosystem services, because inflexible enforcement might limit many ongoing uses of ecosystems. Instead, it can serve as a way to evaluate the ecosystem impacts of management decisions, using a common currency that can be applied across agencies. It can also be used as a "tie-breaker" for different management options that might both fulfill agency mandates, but have very different impacts on biodiversity. By evaluating the impact of different human activities on ecosystem functioning, a focus on biodiversity can serve as a critical indicator of ecosystem status. Implementation would require a governance structure that coordinates among sectoral managers.

We do not argue for maintenance of all natural biodiversity, everywhere, all the time. But we do suggest that the following requirements make good policy and market sense: (1) each agency or management entity understands its role in the conservation of biodiversity, including impacts and benefits derived; (2) each agency focuses at 
(a)

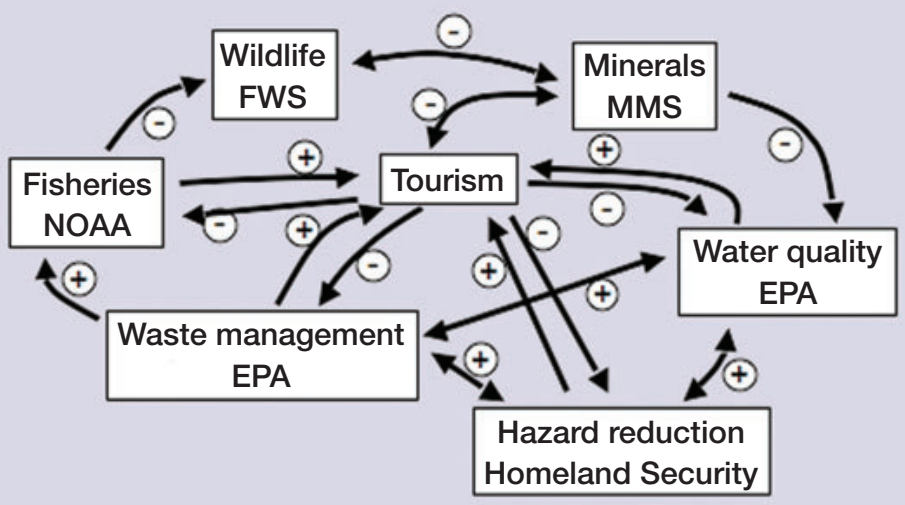

(b)

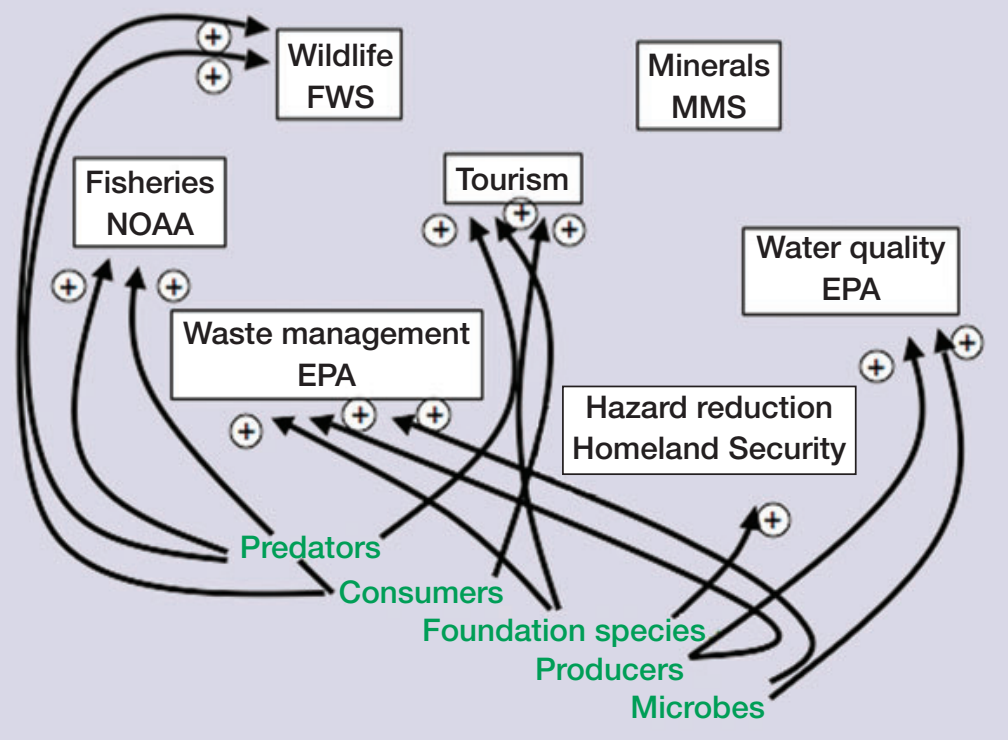

Figure 3. (a) Complex positive and negative correlations among marine ecosystem services create an intricate web of relationships that will be difficult for managers to simultaneously optimize. Environmental changes that affect any one service (eg water quality) will probably impact others as well, making ecosystemwide decisions difficult to achieve. (b) Likely relationships between each ecosystem service and the biodiversity of marine habitats. Positive effects of diversity on services may make it easier to enhance or maintain multiple services at the same time, providing a basis for a coordinated regulatory framework. NOAA = National Oceanic and Atmospheric Administration; EPA = Environmental Protection Agency; FWS = US Fish and Wildlife Service; MMS = Minerals Management Service.

least part of its energies and resources on the conservation of biodiversity; and (3) a coordinated management structure focused on integrated assessments of the environment and human impacts, and on trade-offs between various ocean-use sectors, is created.

We envision that the overall objective for EBM will involve maintaining or optimizing the provision of ecosystem goods and services, subject to a set of constraints that maintain biological diversity. Protecting biological diversity will provide long-term, direct benefits to several ocean-use sectors. Some sectors (eg mineral extraction, transporta- tion) may benefit little from this approach; for these sectors, preservation of biological diversity may serve primarily as a constraint on activities. Yet, even here, a focus on biodiversity could still provide an important framework for evaluating trade-offs among oceanuse sectors. Adopting maintenance of biodiversity as a core element of EBM provides a basis for evaluating cumulative impacts, which can lead to decision tools to guide management of diverse sectors. Our goal would be to define strategies for utilization that minimize impacts on biodiversity, while permitting continuation of ecosystem use and a broad mix of goods and services.

Although our proposal would need to be implemented on a region-by-region basis, it could form the core of a well-defined national strategy focused on biodiversity rather than only on individual ecosystem services. Clearly, the simple idea of focusing on conservation of biodiversity cannot solve every problem. But it could force explicit recognition of the importance of trade-offs among sectors and provide a way of addressing them, as opposed to the current practice of neglecting to document such effects.

\section{How to measure diversity so that we can conserve it}

Using biodiversity as a national master variable to enable EBM will require that it be measured in consistent ways and over the multiple regional, temporal, depth, and geographic scales relevant to management. Such measurement systems are currently lacking (Rosenberg and McLeod 2005). However, web-based tools for biodiversity assessment are now under development and show promise for global information transfer and quality control (Guralnick et al. 2007), as do broadly based marine biodiversity research efforts, such as the international Census of Marine Life and regional Marine Life Observatories. There is also considerable potential for mining additional information from existing datasets. Nevertheless, even for taxa that are well studied, the choice of appropriate metrics has not been completely resolved. For example, the use of species richness as a measure of species diversity fits naturally into existing legal mandates (eg ESA, MSA), but does not address concerns related to loss of ecological function as population levels decline or loss of adaptability as genetic diversity declines.

We suggest that measuring biodiversity in ways that will be useful in a management context probably requires a 
three-tiered approach (Figure 4). First, fundamental measures of biodiversity could be accomplished at the seascape level by mapping distinct biological habitats within regions. Second, monitoring within habitat types for key species would provide assays of species-level diversity. Third, diversity within species, including genetic variability and physiological or life history diversity, adds the last layer (Beck 2003; Guinotte et al. 2006; Pittman et al. 2007). As Sala and Knowlton (2006) point out, "an effort to map marine ecosystems and ecoregions - similar to those conducted for terrestrial ecosystems - will be essential, because conserving habitats to preserve species might be an immediate and practical management strategy, regardless of the number of species present". One of the outstanding challenges is to relate the nature and magnitude of services to the extent of habitats and communities, the biodiversity that they contain, and the types and levels of disturbance they can endure, because there will always be a need to use the marine environment. The goals of conserving biodiversity thereby conserving ecosystem function - and of sustaining human use and benefits require an understanding of the interplay between these factors.

In measuring diversity within habitats, we will need assessment and ongoing monitoring to verify species' occurrence and abundance. Defining habitats within regions and enumerating the species that depend upon them are fundamental requirements. Practical considerations will probably force the adoption of a subset of surrogate taxa, preferably ones that are critical to ecosystem services, as the targets for assessment. These surrogates must include taxa that provide a variety of services, such as habitat-forming species (eg corals, sponges, oysters, seagrasses, kelps), pollutant-recycling species (eg marsh grasses, macroalgae), fisheries species, and microbes, and not just fished species or large fish and invertebrates. Other diversity indicators for the pelagic and deep-sea realms might focus on planktonic prokaryotes and microeukaryotes, thermal vent communities, deep-sea coral and sponge assemblages, seamount communities, mixedspecies fisheries, and sediment microbial communities. Species across the size and phylogenetic spectrum should be included, with the most appropriate candidates being those with the greatest amount of biological knowledge and taxonomic certainty. Based on such evaluation, a set of species should be selected for monitoring (Vecchione et al. 2000). Over time, maps of habitat types and temporal changes in abundance could be combined to paint a dynamic picture of species occurrences over the seascape.

Managing for biodiversity will require the incorporation of new technologies, in addition to established techniques. In particular, biodiversity assessments will necessitate employment of more taxonomists and parataxonomists, as well as the use of information-based tools designed for quicker assessments (Pittman et al. 2007). Certain species (especially microbes) may best be enumerated with DNA arrays or other automated techniques (DeSantis et al 2007). Whatever automation can be applied to these surveys will

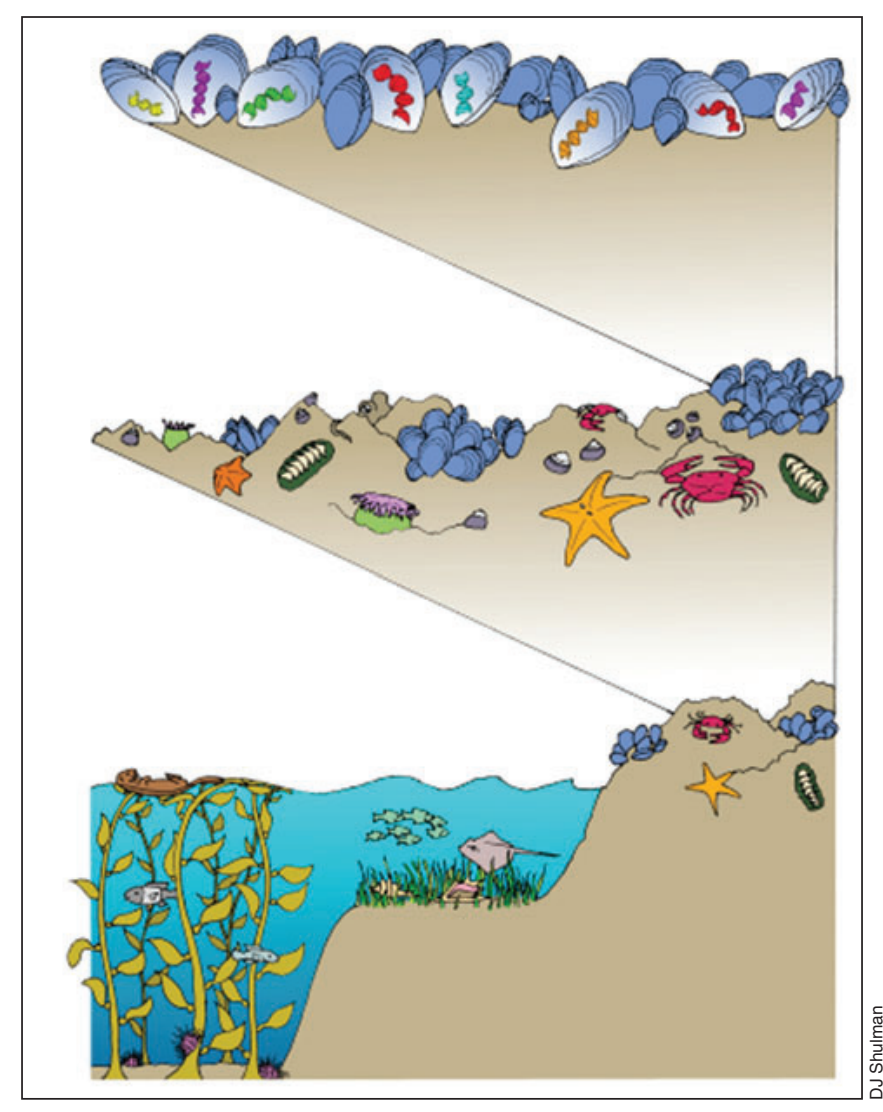

Figure 4. Measurement of biodiversity must occur at several levels. The lower level includes different habitat types within a region - in this case, the rocky intertidal zone, seagrass beds, and kelp forests along the California coast. The middle level focuses on species diversity, here illustrated as the set of macroinvertebrates of the rocky intertidal zone. The upper level represents the diversity within each species, represented here by different DNA types within intertidal mussels.

free resources for measurement of species that cannot be assessed in these ways. Similarly, sophisticated tags for fish and invertebrates can record a variety of environmental and physiological parameters (eg temperature, depth, hormone levels) that may reveal environmental associations that would otherwise be hidden from view (Weng et al. 2005).

Long-term study sites will be critical to effective management in the coming decades, as increasing anthropogenic stressors and climate change affect ocean and coastal ecosystems. A wide range of marine protected areas will be invaluable experimental and control sites for such investigations. To conduct the requisite studies, the scientific community will have to develop new tools for the remote and continuous measurement of microbial diversity, oceanic and coastal zooplankton and phytoplankton, and mega- and meiofauna in the benthos and the ocean. Such tools will probably include genomics; more robust marine biosensors; automated aerial, surface, and underwater drones equipped with sonar or acoustic monitoring; cameras for detection of ocean fauna; other biological monitors and samplers; and new mathematical models to chart energy flow within food webs. Such a combination of efforts amounts to creation of marine life 
observatories that will complement ocean-observing systems focused on physical measurements of the sea.

While new approaches must be developed to acquire consistent measures of biodiversity across all marine habitats, the efforts we outline here have their basis in the current wealth of taxonomic and ecological knowledge. For our approach to become practical, existing data for well-known ecosystems will need to be summarized in a comparative framework. In addition, new data on poorly known ecosystems, especially their taxa, habitats, and levels of natural diversity, need to be collected. The end result would be a system in which information on trends in the biodiversity of marine habitats is accessible to managers and decision makers. Political will is needed to mandate management for conservation of biodiversity and to allocate reasonable resources to support the requisite scientific (eg habitat mapping, taxonomy) and management work.

Case studies that test our concept of managing for biodiversity to sustain ecosystem services are generally lacking, though some ongoing activities appear to offer opportunities for such evaluation. One might be the snapper-grouper fishery in the US South Atlantic Bight. This complex fishery, which includes 73 of the 98 fish species managed by the South Atlantic Fishery Management Council (SAFMC), is administered using a multi-species Fishery Management Plan (see www.safmc.net/ for information and documents). At least in part because many of the species in the snapper-grouper complex are highly dependent on specific habitats, the SAFMC has developed a Habitat Plan as a precursor to a broader Fishery Ecosystem Plan. Although the SAFMC is currently constrained to accommodate only a single ecosystem service (fishing), if the Council included management efforts dealing with biodiversity of the habitats important for the snapper-grouper complex, we believe this would have positive effects on numerous other ecosystem services.

\section{- Future directions and conclusions}

Broadly speaking, new data suggest that biodiversity helps to increase, maintain, and promote marine ecosystem function (Sala and Knowlton 2006; Worm et al. 2006; Hector and Bragchi 2007). The ecological mechanisms of diversity effects, such as complementarity and redundancy, may be widespread in the oceans, making this a general rule. The ecosystem services demanded by humans are complex, and are probably best supported by diverse biological communities (MA 2005). In addition, conservation of biodiversity for its own sake remains a valid and valuable goal for our society; we should do all we can to maintain the rich and fascinating life of this planet (McCauley 2006). Thus, conservation and management of biodiversity include both philosophical and practical concerns. The current rate of decline of ocean ecosystems makes them urgent.

Because sustained diversity is likely to bolster most services, a system managed in a coordinated fashion for diversity will accrue more "ecoservice capital" for human use than do current practices. In almost all investment or allocation schemes, having more capital makes investment choices and conflicts easier to resolve. If we use conservation of biodiversity as a primary aim of EBM, we will automatically also conserve many of the myriad interconnections among species and their environment. These interactions represent a major target of EBM, because they result in essential ecosystem services.

This proposal represents a core idea, but there are many aspects that need to be resolved in any specific application. Acceptable trade-offs between maintaining diversity and modifying it through ecosystem use need to be defined, and are likely to be system specific. There may be cases where direct management of all core ecosystem services simultaneously results in better function than an indirect approach emphasizing biodiversity. In many cases, our simple biodiversity approach might be a starting point of EBM, with more focus on coordinated management of different ecosystem services later. By maintaining biodiversity as a national core variable through conservation of key species, overall species richness, functional diversity, habitat diversity, and variation in genetic diversity within species, we will generate a costeffective way to coordinate diverse agency goals, manage trade-offs in service provision, and ensure maximum ecosystem function and resilience.

\section{Acknowledgements}

This paper is based in part on ideas discussed at a workshop, Approaches for researching the roles of marine and coastal biodiversity in maintaining ecosystem services, sponsored by the US National Committee for the Census of Marine Life (September 11-13, 2006, in Washington, DC). Helpful comments from $\mathrm{H}$ Galindo, $\mathrm{F}$ Holland, $\mathrm{T}$ Hourigan, $\mathrm{F}$ Micheli, M Pinsky, A Rosenberg, M Vecchione, and C Woodley improved the manuscript. We gratefully acknowledge financial support from NOAA's Oceans and Human Health Initiative, Hollings Marine Laboratory, National Marine Fisheries Service, and Office of Ocean Exploration and from the US Department of Energy, the Alfred P Sloan Foundation, the David and Lucile Packard Foundation, and the Betty and Gordon Moore Foundation.

\section{References}

Allison G. 2004. The influence of species diversity and stress intensity on community resistance and resilience. Ecol Monogr 74: $117-34$.

Arkema KK, Abramson SC, and Dewsbury BM. 2006. Marine ecosystem-based management: from characterization to implementation. Front Ecol Environ 4: 525-32.

Beck MW. 2003. The sea around: marine regional planning. In: Groves CR (Ed). Drafting a conservation blueprint: a practitioners' guide to planning for biodiversity. Washington, DC: Island Press.

Bruno JF, Stachowicz JJ, and Bertness MD. 2003. Incorporating facilitation into ecological theory. Trends Ecol Evol 18: 119-25.

Butler SJ, Vickery JA, and Norris K. 2007. Farmland biodiversity and the footprint of agriculture. Science 315: 381-84. 
Byrnes JE, Stachowicz JJ, Hultgren K, et al. 2006. Predator diversity enhances kelp forest trophic cascades by modifying herbivore behavior. Ecol Lett 9: 61-71.

Carpenter SR, DeFries R, Dietz T, et al. 2006. Millennium ecosystem assessment: research needs. Science 314: 257-58.

Coleman ML, Sullivan MB, Martiny AC, et al. 2006. Genomic islands and the ecology and evolution of Procholorcoccus. Science 311: 1768-70.

Covich AP, Austen MC, Barlocher F, et al. 2004. The role of biodiversity in the functioning of freshwater and marine benthic ecosystems. BioScience 54: 767-75.

Daily GC, Alexander SE, Ehrlich PR, et al. 1997. Ecosystem services: benefits supplied to human societies by natural ecosystems. Iss Ecol 2: 1-18.

DeSantis TZ, Brodie EL, Moberg JP, et al. 2007. High-density universal $16 \mathrm{~S}$ rRNA microarray analysis reveals broader diversity than typical clone library when sampling the environment. Microbial Ecol 53: 371-83.

Duffy JE, Richardson JP, and Canuel EA. 2003. Grazer diversity effects on ecosystem functioning in seagrass beds. Ecol Lett 6: 637-45.

Grumbine RE. 1994. What is ecosystem management? Conserv Biol 8: $27-38$.

Guinotte JM, Bartley JD, Iqbal A, et al. 2006. Modeling habitat distribution for organism occurrences and environmental data: case study using anemone fishes and their sea anemone hosts. Mar Ecol-Prog Ser 316: 269-83.

Guralnick PA, Hill AW, and Hill M. 2007. Towards a collaborative, global infrastructure for biodiversity assessment. Ecol Lett 10: 663-72.

Hector A and Bagchi R. 2007. Biodiversity and ecosystem multifunctionality. Nature 448: 188-90.

Hilborn R, Quinn TP, Schindler DE, and Rogers DE. 2003. Biocomplexity and fisheries sustainability. P Natl Acad Sci USA 100: 6564-68.

Hooper DU and Vitousek PM. 1998. Effects of plant composition and diversity on nutrient cycling. Ecol Monogr 68: 121-49.

Hughes AR and Stachowicz JJ. 2004. Genetic diversity enhances the resistance of a seagrass ecosystem to disturbance. P Natl Acad Sci USA 101: 8998-9002.

Kibblewhite MG, Ritz K, and Swift MJ. 2008. Soil health in agricultural systems. Philos T Roy Soc B. doi:10.1098.rstb.2007.2178.

Knowlton N. 1999. The evolution of mutualisms: exploring the paths between conflict and cooperation. Trends Ecol Evol 14: 49-53.

Kohn AJ. 1959. The ecology of Conus in Hawaii. Ecol Monogr 29: 47-90.

Levin SA. 1999. Fragile dominion: complexity and the commons. Reading, MA: Perseus Books.

Loreau M, Naeem S, Inchausti P, et al. 2001. Biodiversity and ecosystem functioning: current knowledge and future challenges. Science 294: 804-08.

McCauley D. 2006. Selling out on nature. Nature 443: 27-28.

MA (Millennium Ecosystem Assessment). 2005. Millennium Ecosystem Assessment: synthesis report. Washington, DC: Island Press.

Naeeem S and Li S. 1997. Biodiversity enhances ecosystem reliability. Nature 390: 507-09.

Norse EA and McManus RE. 1980. Ecology and living resources: biological diversity. In: Environmental quality 1980: the 11th annual report of the Council on Environmental Quality. Washington, DC: Executive Office of the President, Council on Environmental Quality.

Nystrom M and Folke C. 2001. Spatial resilience of coral reefs. Ecosystems 4: 406-17.
Palmer M, Bernhardt M, Chornesky E, et al. 2004. Ecology for a crowded planet. Science 304: 1251-52.

Palumbi SR, McLeod K, and Grumbaugh D. 2008. Ecosystems in action: lessons from marine ecology about recovery, resistance, and reversibility. BioScience 58: 33-42.

Pew Oceans Commission. 2003. America's living ocean: charting a course for sea change. Washington, DC: Pew Trusts.

Pikitch EK, Santora C, Babcock EA, et al. 2004. Ecosystem-based fishery management. Science 305: 346-47.

Pittman SJ, Christensen JD, Caldow C, et al. 2007. Predictive mapping of fish species richness across shallow-water seascapes in the Caribbean. Ecol Model 204: 9-21.

Reusch TBH, Ehlers A, Hammerli A, and Worm B. 2005. Ecosystem recovery after climatic extremes enhanced by genotypic diversity. P Natl Acad Sci USA 102: 2826-31.

Rosenberg AA and McLeod KL. 2005. Implementing ecosystembased approaches to management for the conservation of ecosystem services. In: Browman HI and Stergiou KI (Eds). Politics and socio-economics of ecosystem-based management of marine resources. Mar Ecol-Prog Ser 300: 270-74.

Sala E and Knowlton K. 2006. Global marine biodiversity trends. Annu Rev Environ Resour 31: 93-122.

Stachowicz JJ, Fried H, Osman RW, and Whitlach RB. 2002. Biodiversity, invasion resistance, and marine ecosystem function: reconciling pattern and process. Ecology 83: 2575-90.

Tilman D, Fargione F, Wolff B, et al. 2001. Forecasting agriculturally driven global environmental change. Science 292: 281-84.

Tilman D, Reich P, and Knops JM. 2006. Biodiversity and ecosystem stability in a decade-long grassland experiment. Nature 441: 629-32.

USCOP (US Commission on Ocean Policy). 2004. An ocean blueprint for the 21st century. Final report of the US Commission on Ocean Policy. Washington, DC

US Ocean Action Plan. 2004. The Bush Administration's response to the US Commission on Ocean Policy. Washington, DC.

Vecchione M, Mickevich MF, Fauchald K, et al. 2000. Importance of assessing taxonomic adequacy in determining fishing effects on marine biodiversity. ICES J Mar Sci 57: 677-81.

Wall DH, Bardgett RD, Covich AP, and Snelgrove PVR. 2004. Understanding the functions of biodiversity in soils and sediments will enhance global ecosystem sustainability and societal well-being. In: Wall DH (Ed). Sustaining biodiversity and ecosystem services in soils and sediments. Washington, DC: Island Press.

Weng KC, Castilho PC, Morrissette JM, et al. 2005. Satellite tagging and cardiac physiology reveal niche expansion in salmon sharks. Science 310: 104-06.

Worm B, Barbier EB, Beaumont N, et al. 2006. Impacts of biodiversity loss on ocean ecosystem services. Science 314: 787-90.

Yachi S and Loreau M. 1999. Biodiversity and ecosystem productivity in a fluctuating environment: the insurance hypothesis. P Natl Acad Sci USA 96: 1463-68.

${ }^{7}$ National Center for Ecological Analysis and Synthesis, Santa Barbara, CA; ${ }^{8}$ Aquatic Systems Group, University of Southern Maine, Portland, ME; ${ }^{9}$ Hawaii Institute of Marine Biology, University of Hawaii, Kaneohe, $\mathrm{HI} ;{ }^{10}$ Marine Conservation Biology Institute, Bellevue, WA; ${ }^{11}$ Department of Evolution and Ecology, University of California, Davis, Davis, CA; ${ }^{12}$ Department of Biology and Natural Resource Ecology Laboratory, Colorado State University, Fort Collins, CO 